\title{
Article \\ Discordant Predictions of Extraglandular Involvement in Primary Sjögren's Syndrome According to the Anti-SSA/Ro60 Antibodies Detection Assay in a Cohort Study
}

\author{
Geoffrey Urbanski ${ }^{1,2, *(\mathbb{D}, \text {, Aline Gury }}{ }^{1}$, Pascale Jeannin ${ }^{3,4}$, Alain Chevailler ${ }^{3}$, Pierre Lozac' ${ }^{1,5}$, \\ Pascal Reynier $^{2}$ D, Christian Lavigne ${ }^{1}\left(\mathbb{D}\right.$, Carole Lacout ${ }^{1}$ and Emeline Vinatier ${ }^{3,4}$
}

check for updates

Citation: Urbanski, G.; Gury, A.; Jeannin, P.; Chevailler, A.; Lozac'h, P.; Reynier, P.; Lavigne, C.; Lacout, C.; Vinatier, E. Discordant Predictions of Extraglandular Involvement in Primary Sjögren's Syndrome According to the Anti-SSA/Ro60 Antibodies Detection Assay in a Cohort Study. J. Clin. Med. 2022, 11, 242. https://doi.org/10.3390/ jcm11010242

Academic Editors: Masutaka Furue and Stamatis Gregoriou

Received: 28 November 2021 Accepted: 30 December 2021 Published: 4 January 2022

Publisher's Note: MDPI stays neutral with regard to jurisdictional claims in published maps and institutional affiliations.

Copyright: (C) 2022 by the authors. Licensee MDPI, Basel, Switzerland. This article is an open access article distributed under the terms and conditions of the Creative Commons Attribution (CC BY) license (https:// creativecommons.org/licenses/by/ $4.0 /)$
1 Department of Internal Medicine and Clinical Immunology, University Hospital, 49000 Angers, France; aline.gury@gmail.com (A.G.); pierre.lozac@gmail.com (P.L.); ChLavigne@chu-angers.fr (C.L.); Carole.Lacout@chu-angers.fr (C.L.)

2 Mitolab, MitoVasc Institute, CNRS 6015, INSERM U1083, University of Angers, 49000 Angers, France; pareynier@chu-angers.fr

3 Laboratory of Immunology, University Hospital, 49000 Angers, France; pascale.jeannin@univ-angers.fr (P.J.); chevailler.a@wanadoo.fr (A.C.); Emeline.Vinatier@chu-angers.fr (E.V.)

4 INSERM, CRCINA, Angers University, 49000 Angers, France

5 Department of Internal Medicine, General Hospital, 72000 Le Mans, France

* Correspondence: urbanskigeoffrey@gmail.com; Tel.: +33-(0)2-4135-4003

\begin{abstract}
Electrophoresis-derived techniques for anti-SSA/Ro60 KDa (anti-SSA) antibodies detection have been progressively replaced by methods using non-native antigens. We aimed to compare the patients' phenotypes and the occurrence of extraglandular manifestations in primary Sjögren's syndrome according to the method used to detect anti-SSA antibodies. Sera from patients with a diagnosis of pSS according to ACR/EULAR 2016 criteria between 2008 and 2017 were tested for anti-SSA antibodies using methods with non-native antigens (magnetic bead multiplex assay; line immunoassays) and one with native antigens (counterimmunoelectrophoresis (CIE)). The population was split into three groups according to anti-SSA antibodies status: absence (SSA-), presence in any method except for CIE (SSA+CIE-), and presence in CIE (SSA+CIE+). The patients in the SSA+CIE+ group $(n=70,42.7 \%)$ were ten years younger and presented more immunological activity compared with both the SSA - $(n=80,48.8 \%)$ and SSA+CIE - groups $(n=14,8.5 \%)$. The SSAand SSA $+\mathrm{CIE}-$ groups were poorly distinct. The presence of anti-SSA antibodies solely in CIE was significantly associated with the occurrence of extraglandular manifestations of pSS (HR $=4.45$ (2.35-8.42)). Contrary to CIE, methods using non-native antigens to detect anti-SSA antibodies were unable to predict the occurrence of systemic expression of pSS.
\end{abstract}

Keywords: primary Sjögren's syndrome; anti-SSA antibodies; detection methods

\section{Introduction}

Anti-SSA/Ro60 (anti-SSA) antibodies represent a cornerstone in primary Sjögren's syndrome (pSS). Even if they are not a mandatory criterion for the pSS diagnosis, they are present in $39 \%$ to $73 \%$ of patients from large cohorts depending on recruitment [1-4]. Originally described in 1961 by Anderson and colleagues as SjD antibodies [5], anti-SSA autoantibodies were clearly identified in the sera of patients with primary Sjögren's syndrome using immunodiffusion in 1975 [6]. Even though anti-SSA antibodies are not fully sensitive and specific for pSS, they are an interesting characteristic for studying the pathogenesis of this disease as they appear many years before the first symptoms [7]. Thus, anti-SSA antibodies are a criterion in classification consensus, including the actual ACR/EULAR 2016 consensus [8]. Beyond their use as a diagnostic criteria, the presence of anti-SSA antibodies has been associated with early onset disease, more signs of B cell activity (hypergammaglobulinemia, rheumatoid factors, cryoglobulinemia, and naive/memory B cell imbalance), and 
more extraglandular manifestations in pSS [7,9-13]: Raynaud phenomenon [14], interstitial pneumonia [15], peripheral nerve involvement [14,16-18], cutaneous vasculitis [19-22], cytopenias $[16,19,23,24]$, adenopathies $[14,19,25]$, and lymphoma $[12,25,26]$.

Former gold standard techniques for detecting anti-SSA antibodies were RNA precipitation, double-immunodiffusion, counterimmunoelectrophoresis (CIE), immunoprecipitation, and Western blotting [27]. Among these, CIE seemed to present the best balance between performances and technical constraints [28], as it was quite rapid and able to detect a small concentration of antibody. Moreover, such a method mimics the natural interaction between antigens and antibodies, highlighting autoantibodies able to precipitate (visualised with line of precipitation) [6]. This homemade method was progressively replaced by enzyme-linked immunosorbent assay (ELISA) and line immunoassay (LIA) for cost and time effectiveness reasons [29]. The current widespread method is the automatic multiplex immunoassay using magnetic beads covered with antigens, allowing detection of many antinuclear antibodies quickly and with a low sample volume [30].

To our knowledge, most studies comparing the predictive value of anti-SSA antibodies in pSS did not differentiate between these methods in the interpretation of their results. This could be troubling due to the different analytical conditions of the immunoassays. Indeed, recent and widespread methods (LIA, ELISA, and multiplex assays) use purified or recombinant proteins that are denatured through preparation process or during a coating step, whereas epitopes recognised by anti-SSA antibodies are highly conformational and the binding is often lost with denaturation [31-33]. Identifying antibodies with recombinant or denatured protein raises questions about the ability to reflect the pathological process of the disease and the probability of a false positive [34].

pSS is associated with extraglandular manifestations that reflect the systemic activity of the disease. These manifestations are of interest because they represent the severity of pSS. Identifying markers to predict the occurrence of extraglandular manifestations is thus a major concern.

This study aimed to compare the onset of extraglandular involvement in pSS patients according to the absence or presence of anti-SSA antibodies using three methods of detection: CIE, LIA, and multiplex assays.

\section{Patients and Methods}

\subsection{Ethics}

The study was approved by the Ethical Committees of Angers University Hospital $\left(n^{\circ} 2018 / 55\right)$ and was conducted in compliance with the declaration of Helsinki. All participants gave non-opposition informed consent. This study applied the Strengthening the Reporting of Observational Studies in Epidemiology (STROBE) statement to observational studies.

\subsection{Inclusion and Exclusion Criteria}

We extensively revised the files of patients aged 18 years and over who were referred on suspicion of Sjögren's syndrome in our Internal Medicine Department between January 2008 and December 2017. We included patients with primary Sjögren's syndrome (pSS) according to ACR/EULAR 2016 criteria [8]. We excluded patients with no available serum samples that had been collected during the 24 months following pSS diagnosis. We also excluded patients with secondary Sjögren's syndrome and/or with a follow-up of less than 12 months.

\subsection{Data Collection}

We extracted the following data: age at diagnosis, sex, follow-up duration, presence of eye and/or mouth dryness, results from Schirmer I test and unstimulated whole saliva (UWS) flow rate, results from minor salivary gland biopsy (MSGB), presence of antinuclear antibodies (on HEp-2 cells), anti-SSA, anti-SSB antibodies, rheumatoid factors, cryoglobu- 
linemia, C3 and C4 fractions of complement, hypergammaglobulinemia defined as a blood gammaglobuline level of over $15 \mathrm{~g} / \mathrm{L}$, and extraglandular manifestations, as detailed below.

\subsection{Definition of Extraglandular Manifestations}

We considered extraglandular manifestations to be all measurable items listed in the ESSDAI (European League Against Rheumatism Sjögren's Syndrome Disease Activity Index) score [35] except for constitutional, glandular and biological items. We also excluded non-objective signs, i.e., arthralgia without arthritis and cough. For cytopenia, we only considered a clinically significant level of cytopenia, i.e., a moderate and high degree of activity from ESSDAI (haemoglobin $\leq 100 \mathrm{~g} / \mathrm{L}$; platelets $\leq 100,000 / \mathrm{mm}^{3}$; lymphocytes $\leq 500 / \mathrm{mm}^{3}$; neutrophils $\left.\leq 1000 / \mathrm{mm}^{3}\right)$. All these extraglandular manifestations were considered related to pSS after checking for the exclusion of differential diagnoses, notably for cytopenias. We also considered interstitial cystitis to be an extraglandular manifestation related to pSS [36], even if not listed in ESSDAI. Raynaud phenomenon was not considered to be an extraglandular manifestation. We collected data about small fibre neuropathy but it was treated separately because of its association with the anti-SSA negative form of pSS [18,37,38].

Extraglandular manifestations were split into those occurring before pSS diagnosis and those occurring after.

\subsection{Detection of Anti-SSA Antibodies}

We used serum samples frozen at $-20^{\circ} \mathrm{C}$ and collected during the 24 months following pSS diagnosis. They were all tested for each participant at the same time using all four techniques employed by this study. The presence of anti-SSA60 kDa/Ro (anti-SSA) antibodies was tested for using (i) magnetic bead multiplex assay (Bioplex ${ }^{\circledR} 2200$, ANA screen kit, Biorad, Hercules, CA, USA), (ii) LIA Fullana Dot ${ }^{\circledR}$ (Alphadia, Mons, Belgium) with automated reading on BlueDiver ${ }^{\circledR}$ (Alphadia, Mons, Belgium), and (iii) LIA Inno-Lia ANA $^{\circledR}$ (Fujirebio, Tokyo, Japan) with manual reading. The fourth assay was CIE, adapted from a previously described method [39]. Briefly, we realised an indubiose film at a $\mathrm{pH}$ of 8.2 with barbital buffer. The indubiose plates were dug out of 2 columns of 15 wells in order to alternately deposit test and control sera, and of 2 troughs $3 \mathrm{~mm}$ wide cut parallel to the wells, 1 filled with primate spleen extract and 1 filled with rabbit thymus extract. Electrophoresis was carried out at $12 \mathrm{~mA} /$ slide for $90 \mathrm{~min}$ in barbital buffer. Precipitins were identified $24 \mathrm{~h}$ after the electrophoresis by at least 2 expert readers (A.G., A.C., and C.L. (Carole Lacout) among authors and G.R. in acknowledgements) detecting precipitation lines of identity with reference sera in adjacent wells.

We did not consider in this study anti-TRIM21 antibodies (previously named antiSSA52 kDa) as their target differs from anti-SSA antibodies [40], and as they are not associated with pSS [41].

\subsection{Constitution of Groups}

The whole population was separated in three groups according to the results of antiSSA antibodies detection: patients without anti-SSA antibodies (SSA-), patients with anti-SSA antibodies detected in multiplex and/or LIA but not in CIE (SSA+CIE-), and patients with anti-SSA antibodies detected in CIE whatever the results in multiplex and/or solid phase dots (SSA+CIE+).

\subsection{Statistics}

The quantitative data were presented in medians and quartiles and compared using a one-way ANOVA or Kruskal-Wallis test as appropriate. The categorical data were presented as absolute values and as percentages and were compared using a chi-squared test. The reliability between the tests for anti-SSA antibodies detection was evaluated by means of Cohen's kappa coefficient. 
Time-to-event curves for first incident extraglandular manifestations were presented as Kaplan-Meier curves and were compared with a log-rank test. Follow-up was limited at 120 months.

The influence of covariates on the occurrence of extraglandular manifestation was evaluated with a Cox model. The proportional hazard assumption was checked using 2 different methods: graphically by plotting the log(minuslog) curves and by studying the interaction with time. The alpha risk was 5\%. The hazard ratios (HR) were presented with a confidence interval of 95\%. The analyses were carried out using Graphpad Prism v6.01 (GraphPad Software, La Jolla, CA, USA) and SPSS software v23.0 (IBM Corp, Chicago, IL, USA).

\section{Results}

\subsection{General Characteristics}

From the 310 fully revised files between January 2008 and December 2017, 146 patients were excluded: 88 patients did not fulfil the ACR/EULAR 2016 criteria, 34 patients had secondary Sjögren's syndrome, no serum sample was available for 18 patients, and 6 were excluded because of a follow-up time of less than 12 months. The study population included 164 patients with a median age of 59 (46-70) years and was composed of $140(85.3 \%)$ females. Anti-SSA antibodies were detected in $84(51.2 \%)$ patients, whatever the detection assay. The SSA - , SSA+CIE - , and SSA+CIE+ groups consisted of 80 (48.8\%), 14 (8.5\%), and 70 (42.7\%) patients, respectively. There was no patient with sole positivity for anti-SSA antibodies in the solid phase dots (i.e., positive for one or two of them, and negative for multiplex and for CIE) that could define a specific group. The characteristics of the three groups are detailed in Table 1.

Table 1. General characteristics of patients from the 3 groups and detailed listing of extraglandular manifestations known before pSS diagnosis.

\begin{tabular}{|c|c|c|c|c|}
\hline Groups & SSA- & SSA+CIE- & SSA+CIE+ & $p$-Value \\
\hline Number of patients & 80 & 14 & 70 & \\
\hline Sex (female) $n(\%)$ & $64(80 \%)$ & $13(92.9 \%)$ & $63(90 \%)$ & 0.16 \\
\hline Age at diagnosis (years) & $61(50.8-71)$ & $64.5(43.3-67.8)$ & $52(41.3-66)$ & 0.008 \\
\hline Follow-up duration (months) & $37.5(17.8-67)$ & $99.5(33.8-120)$ & $47(30.3-120)$ & 0.01 \\
\hline Subjective dry eye syndrome $n(\%)$ & $70(87.8 \%)$ & $11(78.6 \%)$ & $59(84.3 \%)$ & 0.65 \\
\hline Subjective dry mouth syndrome $n(\%)$ & $75(93.8 \%)$ & $13(92.9 \%)$ & $60(85.7 \%)$ & 0.24 \\
\hline \multicolumn{5}{|l|}{ ACR/EULAR 2016 criteria $n(\%)$} \\
\hline Schirmer I test $\leq 5 \mathrm{~mm} / 5 \mathrm{~min}$ & $68(85 \%)$ & $9(64.3 \%)$ & $41(58.6 \%)$ & 0.001 \\
\hline UWS flow rate $\leq 1.5 \mathrm{~mL} / 15 \mathrm{~min}$ & $41(51.3 \%)$ & $2(14.3 \%)$ & $33(47.1 \%)$ & 0.04 \\
\hline Anti-SSA antibodies & $0(0 \%)$ & $14(100 \%)$ & $70(100 \%)$ & - \\
\hline Focus score $\geq 1$ on Minor Salivary Gland Biopsy & $80(100 \%)$ & $8(57.1 \%)$ & $64(91.4 \%)$ & - \\
\hline \multicolumn{5}{|l|}{ Other immunological features $n(\%)$} \\
\hline Anti-SSB antibodies & $4(5 \%)$ & $3(21.4 \%)$ & $49(70 \%)$ & $<0.0001$ \\
\hline Antinuclear antibodies titer $\geq 1 / 320$ & $21(26.3 \%)$ & $6(42.9 \%)$ & $62(88.6 \%)$ & $<0.0001$ \\
\hline Hypergammaglobulinemia (over $15 \mathrm{~g} / \mathrm{L}$ ) & $5(6.3 \%)$ & $2(14.3 \%)$ & $31(44.3 \%)$ & $<0.0001$ \\
\hline Presence of rheumatoid factors & $12(15 \%)$ & $2(14.3 \%)$ & $45(64.3 \%)$ & $<0.0001$ \\
\hline Decreased level of C3 and/or C4 & $12(15 \%)$ & $0(0 \%)$ & $17(24.3 \%)$ & 0.06 \\
\hline Cryoglobulinemia & $9(11.3 \%)$ & $0(0 \%)$ & $17(24.3 \%)$ & 0.02 \\
\hline
\end{tabular}


Table 1. Cont.

\begin{tabular}{|c|c|c|c|c|}
\hline Groups & SSA- & SSA+CIE- & SSA+CIE+ & $p$-Value \\
\hline \multicolumn{5}{|l|}{ Detection of anti-SSA antibodies $n(\%)$} \\
\hline Multiplex & $0(0 \%)$ & $14(100 \%)$ & $66(94.3 \%)$ & - \\
\hline LIA (Fullana Dot ${ }^{\circledR}$ ) & $0(0 \%)$ & $12(85.7 \%)$ & $63(90 \%)$ & - \\
\hline LIA (Inno-Lia ANA ${ }^{\circledR}$ ) & $0(0 \%)$ & $4(28.6 \%)$ & $59(84.3 \%)$ & - \\
\hline CIE & $0(0 \%)$ & $0(0 \%)$ & $70(100 \%)$ & - \\
\hline $\begin{array}{l}\text { Extraglandular manifestations occurring before the pSS } \\
\text { diagnosis } n(\%)\end{array}$ & $12(15 \%)$ & $0(0 \%)$ & $6(8.6 \%)$ & 0.18 \\
\hline \multicolumn{5}{|l|}{ Extraglandular manifestations according to ESSDAI } \\
\hline Lymphadenopathy and/or splenomegaly & $0(0 \%)$ & $0(0 \%)$ & $1(1.4 \%)$ & 0.51 \\
\hline Lymphoma & $0(0 \%)$ & $0(0 \%)$ & $0(0 \%)$ & $>0.99$ \\
\hline Arthritis & $0(0 \%)$ & $0(0 \%)$ & $2(2.9 \%)$ & 0.26 \\
\hline Skin & $1(1.3 \%)$ & $0(0 \%)$ & $0(0 \%)$ & 0.59 \\
\hline Lung & $3(3.8 \%)$ & $0(0 \%)$ & $2(2.9 \%)$ & 0.75 \\
\hline Kidney & $0(0 \%)$ & $0(0 \%)$ & $0(0 \%)$ & $>0.99$ \\
\hline Muscle & $0(0 \%)$ & $0(0 \%)$ & $0(0 \%)$ & $>0.99$ \\
\hline Peripheral nervous system & $6(7.5 \%)$ & $0(0 \%)$ & $1(1.4 \%)$ & 0.13 \\
\hline Central nervous system & $0(0 \%)$ & $0(0 \%)$ & $1(1.4 \%)$ & 0.51 \\
\hline Cytopenia & $2(2.5 \%)$ & $0(0 \%)$ & $1(1.4 \%)$ & 0.77 \\
\hline Anaemia & $1(1.3 \%)$ & $0(0 \%)$ & $1(1.4 \%)$ & 0.91 \\
\hline Thrombopenia & $1(1.3 \%)$ & $0(0 \%)$ & $0(0 \%)$ & 0.59 \\
\hline Lymphopenia & $0(0 \%)$ & $0(0 \%)$ & $0(0 \%)$ & $>0.99$ \\
\hline Neutropenia & $0(0 \%)$ & $0(0 \%)$ & $0(0 \%)$ & $>0.99$ \\
\hline \multicolumn{5}{|l|}{ Extraglandular manifestations not listed in ESSDAI } \\
\hline Interstitial cystitis & $1(1.3 \%)$ & $0(0 \%)$ & $0(0 \%)$ & 0.59 \\
\hline \multicolumn{5}{|l|}{$\begin{array}{l}\text { Other manifestations related to pSS (before or after } \\
\text { diagnosis) }\end{array}$} \\
\hline Small fibre neuropathy & $11(13.8 \%)$ & $0(0 \%)$ & $2(2.9 \%)$ & 0.02 \\
\hline $\begin{array}{l}\text { Enlarged parotid and/or lachrymal/submandibular } \\
\text { gland swelling }\end{array}$ & $10(12.5 \%)$ & $1(7.1 \%)$ & $10(14.3 \%)$ & 0.76 \\
\hline Arthralgia with morning stiffness over $30 \mathrm{~min}$ & $17(21.3 \%)$ & $3(21.4 \%)$ & $28(40 \%)$ & 0.03 \\
\hline
\end{tabular}

Notes: Cytopenia as listed in ESSDAI for score 'moderate' and 'high': haemoglobin $\leq 100 \mathrm{~g} / \mathrm{L}$; platelets $\leq 100,000 / \mathrm{mm}^{3}$; lymphocytes $\leq 500 / \mathrm{mm}^{3}$; neutrophils $\leq 1000 / \mathrm{mm}^{3}$. Continuous variables are presented with median and quartiles. CIE: counterimmunoelectrophoresis. ESSDAI: EULAR Sjögren's syndrome disease activity index. LIA: line immunoassay. pSS: primary Sjögren's syndrome. UWS: unstimulated whole saliva.

The SSA+CIE+ group was composed of younger patients compared with the two other groups $(p=0.008$ ), with these patients being around ten years younger. They also displayed more immunological signs of activity (presence of antinuclear antibodies, hypergammaglobulinemia, rheumatoid factors, and cryoglobulinemia) compared with the SSA - and $\mathrm{SSA}+\mathrm{CIE}-$ groups.

We chose not to compare the frequency of a focus score of $\geq 1$ on the MSGB between each group as it was necessarily $100 \%$ in the SSA - group. However, it is important to note that $6 / 14(42.9 \%)$ patients from the SSA+CIE- group had a focus score of $<1$ on the MSGB, compared with $6 / 70(8.6 \%)$ in the SSA+CIE+ group.

The type of extraglandular manifestations occurring before pSS diagnosis did not differ between the three groups. However, even in the absence of statistical difference, 
inaugural extraglandular manifestations were slightly more frequent in the SSA - group (Table 1). In contrast, patients from the SSA+CIE+ group declared inflammatory arthralgia more frequently.

\subsection{Detection of Anti-SSA Antibodies}

All patients from the SSA+CIE - group had anti-SSA antibodies detected in multiplex contrary to the SSA+CIE+ group in which $4(5.7 \%)$ patients were negative for multiplex. Those four patients were also negative for both LIA.

The reliability between the two LIA themselves was poor (kappa $=0.125$ ) for the $\mathrm{SSA}+\mathrm{CIE}-$ group and good (kappa $=0.62)$ for the SSA+CIE+ group. In the SSA+CIE+ group, multiplex had good (kappa $=0.706)$ and moderate $($ kappa $=0.491)$ reliability with the LIA Fullana $\operatorname{Dot}^{\circledR}$ and the LIA Inno-Lia ANA ${ }^{\circledR}$ dots, respectively.

\subsection{Occurrence of Extraglandular Manifestations after pSS Diagnosis}

The characteristics of extraglandular manifestations occurring after pSS diagnosis are detailed in Table 2. Cytopenia, skin, and muscle involvements were more frequent in the $\mathrm{SSA}+\mathrm{CIE}+$ group.

Table 2. Details of extraglandular manifestations occurring after pSS diagnosis.

\begin{tabular}{|c|c|c|c|c|}
\hline Groups & SSA- & SSA+CIE- & SSA+CIE+ & $p$-Value \\
\hline Number of patients & 80 & 14 & 70 & \\
\hline Extraglandular manifestations occurring after the pSS diagnosis $n(\%)$ & $14(17.5 \%)$ & $2(14.3 \%)$ & $37(52.9 \%)$ & $<0.0001$ \\
\hline \multicolumn{5}{|l|}{ Extraglandular manifestations according ESSDAI } \\
\hline Lymphadenopathy and/or splenomegaly & $0(0 \%)$ & $0(0 \%)$ & $4(5.7 \%)$ & 0.06 \\
\hline Lymphoma & $2(2.5 \%)$ & $0(0 \%)$ & $1(1.4 \%)$ & 0.77 \\
\hline Arthritis & $0(0 \%)$ & $0(0 \%)$ & $4(5.7 \%)$ & 0.06 \\
\hline Skin & $1(1.3 \%)$ & $0(0 \%)$ & $10(14.3 \%)$ & 0.004 \\
\hline Lung & $7(8.8 \%)$ & $1(7.1 \%)$ & $9(12.9 \%)$ & 0.65 \\
\hline Kidney & $1(1.3 \%)$ & $0(0 \%)$ & $2(2.9 \%)$ & 0.66 \\
\hline Muscle & $0(0 \%)$ & $0(0 \%)$ & $5(7.1 \%)$ & 0.03 \\
\hline Peripheral nervous system & $6(7.5 \%)$ & $1(7.1 \%)$ & $5(7.1 \%)$ & $>0.99$ \\
\hline Central nervous system & $0(0 \%)$ & $0(0 \%)$ & $1(1.4 \%)$ & 0.51 \\
\hline Cytopenia & $3(3.8 \%)$ & $0(0 \%)$ & $12(17.1 \%)$ & 0.008 \\
\hline Anaemia & $1(1.3 \%)$ & $0(0 \%)$ & $5(7.1 \%)$ & 0.12 \\
\hline Thrombopenia & $2(2.5 \%)$ & $0(0 \%)$ & $6(8.6 \%)$ & 0.15 \\
\hline Lymphopenia & $0(0 \%)$ & $0(0 \%)$ & $1(1.4 \%)$ & 0.51 \\
\hline Neutropenia & $0(0 \%)$ & $0(0 \%)$ & $2(2.9 \%)$ & 0.26 \\
\hline \multicolumn{5}{|l|}{ Extraglandular manifestations not listed in ESSDAI } \\
\hline Interstitial cystitis & $1(1.3 \%)$ & $0(0 \%)$ & $0(0 \%)$ & 0.59 \\
\hline
\end{tabular}

Notes: Cytopenia as listed in ESSDAI for score 'moderate' and 'high': haemoglobin $\leq 100 \mathrm{~g} / \mathrm{L}$; platelets $\leq 100,000 / \mathrm{mm}^{3}$; lymphocytes $\leq 500 / \mathrm{mm}^{3}$; neutrophils $\leq 1000 / \mathrm{mm}^{3}$. Continuous variables are presented with median and quartiles. CIE: counterimmunoelectrophoresis. ESSDAI: EULAR Sjögren's syndrome disease activity index. pSS: primary Sjögren's syndrome. UWS: unstimulated whole saliva.

On the curves for extraglandular manifestations-free survival, the SSA+CIE+ group significantly differed from the two other groups $(p<0.0001$, Figure 1$)$, whereas there was no difference between the SSA - and SSA+CIE- groups $(p=0.58)$. In the Cox regression model, age ( $\mathrm{HR}=1.03(1.01-1.05))$ and especially the presence of anti-SSA antibodies in CIE $(\mathrm{HR}=4.45$ (2.35-8.42)) were significantly associated with the occurrence of extraglandular manifestations (Table 3). 


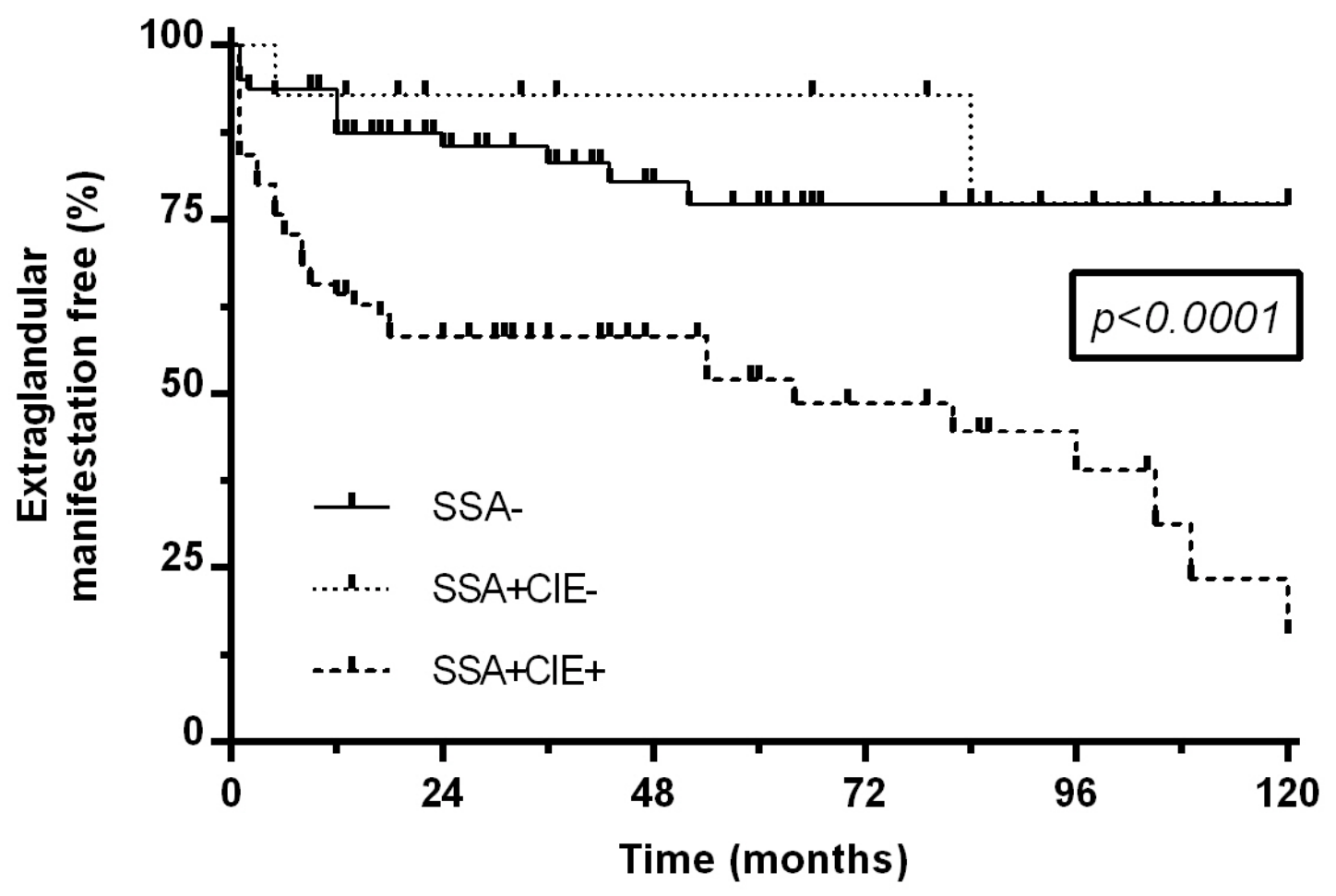

Figure 1. Extraglandular manifestations occurring after diagnosis in the 3 groups. Notes: the SSA - group referred to the patients with no anti-SSA antibodies. The SSA+CIE - referred to the patients with anti-SSA antibodies in any techniques except for counterimmunoelectrophoresis. The SSA+CIE+ referred to the patients with anti-SSA antibodies in counterimmunoelectrophoresis. CIE: counterimmunoelectrophoresis. The $p$-value on the graph represents the results of the comparison between the three curves using the log-rank test.

Table 3. Strength of association between incident extraglandular manifestations and anti-SSA antibodies status.

\begin{tabular}{lcc}
\hline & Hazard Ratio (95\%CI) & $p$-Value \\
\hline \multicolumn{1}{l}{ Anti-SSA antibodies status } & Reference & \\
\hline SSA - & $0.59(0.13-2.66)$ & 0.49 \\
\hline SSA+CIE- & $4.45(2.35-8.42)$ & 0.000005 \\
\hline SSA+CIE+ & $1.03(1.01-1.05)$ & 0.002 \\
\hline Age $^{\text {a }}$ & $0.90(0.38-2.15)$ & 0.82 \\
\hline Sex (female) & $1.39(0.62-3.12)$ & 0.43 \\
\hline $\begin{array}{l}\text { Presence of extraglandular } \\
\text { manifestations before the pSS diagnosis }\end{array}$ & & \\
\hline
\end{tabular}

Notes: The influence of covariates on the occurrence of extraglandular manifestation was evaluated with a Cox model. The proportional hazard assumption was checked with 2 different methods: graphically by plotting the $\log ($ minuslog) curves and by studying the interaction with time. CIE: counterimmunoelectrophoresis. pSS: primary Sjögren's syndrome. ${ }^{a}$ Age as continuous variable.

\subsection{Details inside the Groups}

In the SSA+CIE - group, 6/14 (42.9\%) patients did not present a focus score of $\geq 1$ on the MSGB. None of those 6 patients had extraglandular manifestations either before or after the diagnosis (Supplemental Figure S1). They also did not present inflammatory arthralgia and small fibre neuropathy. Those 6 patients also had no B lymphocyte signs of hyperactivity (hypergammaglobulinemia, rheumatoid factors, low C3 or C4, cryoglobulinemia) except 1 patient, presenting antinuclear antibodies with a titer of $1 / 640$. 
Among the SSA+CIE+ group, $4 / 70(5.7 \%)$ patients had positive anti-SSA antibodies detected only with CIE (i.e., negative for multiplex and dots assays), with three patients having extraglandular manifestations (that appeared before or after the diagnosis for one and two patients, respectively), with a median follow-up time of 36.5 [23-65.3] months. The fourth patient without extraglandular manifestation suffered from inflammatory arthralgia.

\section{Discussion}

With $85 \%$ females, a median age at diagnosis of 56 years, and $51 \%$ patients presenting anti-SSA antibodies, the general characteristics of our study population were consistent with the characteristics of published large cohorts [1-4]. Including all extraglandular manifestations (before and after diagnosis), 96/164 (58.5\%) patients presented at least one extraglandular involvement in our whole population. This rate is quite similar to the cohorts of Baldini et al. (46.6\%) [3] and Seror et al. (69.6\%) [2], with minor differences, particularly less joint involvement compared with teams with rheumatologic department recruitment.

Anti-SSA antibodies have been historically associated with pSS on the basis of a detection method that uses the native structure of the antigen and highlights autoantibodies able to precipitate (visualised with line of precipitation) [6]. Since then, detection methods have evolved using non-native antigens for cost and time effectiveness reasons. However, the epitopes recognised by anti-SSA antibodies are highly conformational [31-33] and little is known about the consequences in clinical expression of detecting autoantibodies which recognise non-native antigens. In this study, we demonstrated that patients with anti-SSA antibodies detected using only denaturing methods were not so rare, concerning 14/84 $(16.7 \%)$ of those having anti-SSA antibodies, and that they presented a significantly reduced extraglandular expression of pSS compared with those with anti-SSA antibodies detected using a precipitating method.

Over the past three decades, anti-SSA antibodies have been largely associated with extraglandular involvement in pSS [7,9-13]. Sandhya et al. noticed an odds ratio of 2.67 [1.09-6.54] of having an extraglandular manifestation in pSS patients presenting anti-SSA antibodies [42]. However, for most of these studies, the methods for assessing the antiSSA antibodies are not specified and, for the few including it in the methods part, a single method was used. With the present study, we have demonstrated that the type of techniques used to detect anti-SSA antibodies, whether using native or denatured antigens, had an important impact on the ability to predict the systemic expression of pSS. Indeed, patients from the group with anti-SSA antibodies not detected in CIE had a weak pSS systemic expression, similar to those without anti-SSA antibodies (HR $=0.59$ [0.13-2.66]). They also shared general characteristics, notably a close age at diagnosis, and were more than ten years older than patients with positivity on CIE; whereas, it is known in the literature that patients with anti-SSA antibodies are around 10 years younger compared with those without these antibodies [7,9-13]. Patients from the SSA+CIE- group clearly presented less frequent signs of B lymphocyte hyperactivity compared with patients with positive CIE. To summarise, the clinical and biological phenotypes of the patients with anti-SSA antibodies for only denaturing methods appeared as if they had no anti-SSA antibodies. Scofield et al. already noticed that the presence of neuropathy in pSS was associated with anti-SSA antibodies when determined using double immunodiffusion, another method that uses native antigens, but not when determined by ELISA [43]. To the best of our knowledge, our study is the first to highlight such findings for extraglandular involvements globally.

We demonstrated that patients with anti-SSA antibodies, which were undetectable with CIE, had a weak pSS systemic expression and were comparable to the SSA-group. This would first lead one to hypothesise the identification of a not yet pathogenic autoantibody in the case of latent autoimmune disease. However, when we detailed the composition of this group of patients, we noticed that $6 / 14(43 \%)$ did not present significant sialadenitis on the MSGB, although they present sicca syndrome. This means that, without anti-SSA antibodies detection by multiplex and/or dots, those patients would not fulfil the criteria for pSS according to the ACR/EULAR consensus [1]. Moreover, none of these patients 
had extraglandular manifestations and swelling of the exocrine glands, whether before or after the diagnosis of pSS. These findings raise questions about a false positivity for these 6 patients among the $84(7.1 \%)$ with anti-SSA antibodies. If the inability of anti-SSA antibodies detected using denaturing methods to predict the systemic expression of pSS is an interesting finding, such a false positive rate represents a more problematic question.

On the other hand, $4 / 84(4.8 \%)$ patients presented anti-SSA antibodies only detected on $\mathrm{CIE}$ and all had a systemic expression of pSS. This confirms that denaturing methods failed to detect anti-SSA antibodies in some patients with a significant expression of pSS [44].

Among the four methods of detection we used, the main cleavage appeared between multiplex and CIE. The solid phase dots did not seem to define a third group compared with multiplex and CIE. Indeed, among patients with possible false positivity (presence of anti-SSA antibodies but negative on CIE and no significant sialadenitis), dots were positive for 5 patients out of 6 .

One limitation of our study is the absence of ELISA, another common method to detect anti-SSA antibodies. However, some authors reported similar results to ours when using those assays, identifying a profile that did not correlate with the patient's clinical presentation $[45,46]$ and a significant false positivity rate for ELISA $(5 / 12,41.7 \%)$ compared with double immunodiffusion and immunoprecipitation [47].

A second limitation of our study could be the definition of extraglandular manifestations, which differed slightly from ESSDAI, for example. However, we thought it important to only consider objective and significant involvements in order to represent the systemic activity of pSS as clinically relevant. For example, the clinical significance of thrombopenia between 100,000 and $150,000 / \mathrm{mm}^{3}$ is limited. We also chose to exclude small fibre neuropathy from extraglandular manifestations because it has been associated with the profile of patients without anti-SSA antibodies $[18,37,38]$ and it constituted a potential bias by overexpressing systemic involvement with this sole neurologic feature. The third limitation is the retrospective design of the study. We tried to correct this point by testing sera collected up to a maximum of 24 months following diagnosis and by analyzing all samples at the same time. Data collection was retrospective, but we have well-structured clinical activity concerning pSS with standardised procedures that minimise this bias. Finally, we have preferred to separate the manifestations occurring before and after pSS diagnosis because it is difficult to precisely define a starting point of the disease in pSS. Moreover, considering involvement before pSS diagnosis would have induced a bias of overestimation of events in patients presenting with extraglandular involvement compared with those presenting with sicca syndrome, possibly resulting in imbalance within the groups.

\section{Conclusions}

In this study, we highlighted that the method used to detect anti-SSA antibodies is a major concern. Methods using denatured antigens were unable to predict the occurrence of systemic expression of pSS contrary to CIE. Patients with anti-SSA antibodies that were undetectable with CIE (no line of precipitation) did not significantly differ from patients without anti-SSA antibodies. Moreover, our study suggests a potential false positivity for the diagnosis of pSS in patients without significant sialadenitis and with non-precipitating anti-SSA antibodies (only identified using denaturing methods). Our results raise questions regarding the value of using only non-native methods to detect anti-SSA antibodies in pSS.

Supplementary Materials: The following are available online at https:/ /www.mdpi.com/article/10 $.3390 /$ jcm11010242/s1, Figure S1: Extraglandular manifestations occurring after diagnosis according to the presence or absence of significant sialadenitis in the SSA+CIE- group.

Author Contributions: Conceptualization, G.U.; methodology, G.U., A.G. and E.V.; software, G.U. and E.V.; validation, G.U., A.G., P.J., C.L. (Carole Lacout) and E.V.; formal analysis, G.U., A.G., P.J., C.L. (Carole Lacout) and E.V.; investigation, G.U., A.G., P.L., P.R., C.L. (Christian Lavigne), C.L. (Carole Lacout) and E.V.; resources, G.U., P.J., A.C., P.R. and E.V.; data curation, G.U., A.G., A.C., C.L. (Carole Lacout) and E.V.; writing-original draft preparation, G.U., A.G. and E.V.; writing- 
review and editing, G.U., A.G., P.J., A.C., P.L., P.R., C.L. (Christian Lavigne), C.L. (Carole Lacout) and E.V.; visualization, G.U., A.G., P.L., P.R., C.L. (Christian Lavigne), C.L. (Carole Lacout) and E.V.; supervision, G.U., P.J., A.C., P.R., C.L. (Christian Lavigne) and E.V.; project administration, G.U., P.J., A.C. and E.V. All authors have read and agreed to the published version of the manuscript.

Funding: This research received no external funding.

Institutional Review Board Statement: The study was conducted in accordance with the Declaration of Helsinki, and approved by the Ethical Committees of Angers University Hospital ( $\left.\mathrm{n}^{\circ} 2018 / 55\right)$.

Informed Consent Statement: The participants gave non-opposition informed consent.

Data Availability Statement: The data presented in this study are available on request from the corresponding author.

Acknowledgments: We wish to deeply thank Gilles Renier, for having imparted to us his great expertise in counterimmunoelectrophoresis.

Conflicts of Interest: The authors declare no conflict of interest.

\section{References}

1. Daniels, T.E.; Criswell, L.A.; Shiboski, C.; Shiboski, S.; Lanfranchi, H.; Dong, Y.; Schiødt, M.; Umehara, H.; Sugai, S.; Challacombe, S.; et al. An Early View of the International Sjögren's Syndrome Registry. Arthritis Rheum. 2009, 61, 711-714. [CrossRef] [PubMed]

2. Seror, R.; Gottenberg, J.E.; Devauchelle-Pensec, V.; Dubost, J.J.; Le Guern, V.; Hayem, G.; Fauchais, A.-L.; Goeb, V.; Hachulla, E.; Hatron, P.Y.; et al. European League Against Rheumatism Sjögren's Syndrome Disease Activity Index and European League Against Rheumatism Sjögren's Syndrome Patient-Reported Index: A Complete Picture of Primary Sjögren's Syndrome Patients: ESSDAI and ESSPRI for Evaluation of Primary SS. Arthritis Care Res. 2013, 65, 1358-1364. [CrossRef]

3. Baldini, C.; Pepe, P.; Quartuccio, L.; Priori, R.; Bartoloni, E.; Alunno, A.; Gattamelata, A.; Maset, M.; Modesti, M.; Tavoni, A.; et al. Primary Sjögren's Syndrome as a Multi-Organ Disease: Impact of the Serological Profile on the Clinical Presentation of the Disease in a Large Cohort of Italian Patients. Rheumatology 2014, 53, 839-844. [CrossRef] [PubMed]

4. $\quad$ Brito-Zerón, P.; Acar-Denizli, N.; Ng, W.-F.; Zeher, M.; Rasmussen, A.; Mandl, T.; Seror, R.; Li, X.; Baldini, C.; Gottenberg, J.-E.; et al. How Immunological Profile Drives Clinical Phenotype of Primary Sjögren's Syndrome at Diagnosis: Analysis of 10,500 Patients (Sjögren Big Data Project). Clin. Exp. Rheumatol. 2018, 36 (Suppl. S112), 102-112.

5. Anderson, J.R.; Gray, K.G.; Beck, J.S.; Kinnear, W.F. Precipitating Autoantibodies in Sjogren's Disease. Lancet Lond. Engl. 1961, 2, 456-460. [CrossRef]

6. Alspaugh, M.A.; Tan, E.M. Antibodies to Cellular Antigens in Sjögren's Syndrome. J. Clin. Investig. 1975, 55, 1067-1073. [CrossRef] [PubMed]

7. Theander, E.; Jonsson, R.; Sjöström, B.; Brokstad, K.; Olsson, P.; Henriksson, G. Prediction of Sjögren's Syndrome Years Before Diagnosis and Identification of Patients With Early Onset and Severe Disease Course by Autoantibody Profiling. Arthritis Rheumatol. 2015, 67, 2427-2436. [CrossRef]

8. Shiboski, C.H.; Shiboski, S.C.; Seror, R.; Criswell, L.A.; Labetoulle, M.; Lietman, T.M.; Rasmussen, A.; Scofield, H.; Vitali, C.; Bowman, S.J.; et al. 2016 American College of Rheumatology/European League Against Rheumatism Classification Criteria for Primary Sjögren's Syndrome: A Consensus and Data-Driven Methodology Involving Three International Patient Cohorts. Arthritis Rheumatol. 2017, 69, 35-45. [CrossRef]

9. Pease, C.T.; Shattles, W.; Charles, P.J.; Venables, P.J.; Maini, R.N. Clinical, Serological, and HLA Phenotype Subsets in Sjögren's Syndrome. Clin. Exp. Rheumatol. 1989, 7, 185-190.

10. Mavragani, C.P.; Tzioufas, A.G.; Moutsopoulos, H.M. Sjögren's Syndrome: Autoantibodies to Cellular Antigens. Clinical and Molecular Aspects. Int. Arch. Allergy Immunol. 2000, 123, 46-57. [CrossRef]

11. Martel, C.; Gondran, G.; Launay, D.; Lalloué, F.; Palat, S.; Lambert, M.; Ly, K.; Loustaud-Ratti, V.; Bezanahary, H.; Hachulla, E.; et al. Active Immunological Profile Is Associated with Systemic Sjögren's Syndrome. J. Clin. Immunol. 2011, 31, 840-847. [CrossRef] [PubMed]

12. Quartuccio, L.; Baldini, C.; Bartoloni, E.; Priori, R.; Carubbi, F.; Corazza, L.; Alunno, A.; Colafrancesco, S.; Luciano, N.; Giacomelli, R.; et al. Anti-SSA/SSB-Negative Sjögren's Syndrome Shows a Lower Prevalence of Lymphoproliferative Manifestations, and a Lower Risk of Lymphoma Evolution. Autoimmun. Rev. 2015, 14, 1019-1022. [CrossRef]

13. Barcelos, F.; Martins, C.; Madeira, N.; Ângelo-Dias, M.; Cardigos, J.; Alves, N.; Vaz-Patto, J.; Cunha-Branco, J.; Borrego, L.-M. Lymphocyte Subpopulations in Sjögren's Syndrome Are Distinct in Anti-SSA-Positive Patients and Related to Disease Activity. Clin. Rheumatol. 2021. [CrossRef] [PubMed]

14. García-Carrasco, M.; Ramos-Casals, M.; Rosas, J.; Pallarés, L.; Calvo-Alen, J.; Cervera, R.; Font, J.; Ingelmo, M. Primary Sjögren Syndrome: Clinical and Immunologic Disease Patterns in a Cohort of 400 Patients. Medicine 2002, 81, 270-280. [CrossRef]

15. Dong, X.; Gao, Y.-L.; Lu, Y.; Zheng, Y. Characteristics of Primary Sjögren's Syndrome Related Lymphocytic Interstitial Pneumonia. Clin. Rheumatol. 2021, 40, 601-612. [CrossRef] [PubMed] 
16. Ramos-Casals, M.; Solans, R.; Rosas, J.; Camps, M.T.; Gil, A.; del Pino-Montes, J.; Calvo-Alen, J.; Jiménez-Alonso, J.; Micó, M.-L.; Beltrán, J.; et al. Primary Sjögren Syndrome in Spain: Clinical and Immunologic Expression in 1010 Patients. Medicine 2008, 87, 210-219. [CrossRef]

17. Ter Borg, E.-J.; Kelder, J.C. Is Extra-Glandular Organ Damage in Primary Sjögren's Syndrome Related to the Presence of Systemic Auto-Antibodies and/or Hypergammaglobulinemia? A Long-Term Cohort Study with 110 Patients from the Netherlands. Int. J. Rheum. Dis. 2017, 20, 875-881. [CrossRef]

18. Lacout, C.; Cassereau, J.; Lozac'h, P.; Gury, A.; Ghali, A.; Lavigne, C.; Letournel, F.; Urbanski, G. Differences in Clinical Features between Small Fiber and Sensitive Large Fiber Neuropathies in Sjögren's Syndrome. Eur. J. Intern. Med. 2020, 79, 58-62. [CrossRef]

19. Alexander, E.L.; Arnett, F.C.; Provost, T.T.; Stevens, M.B. Sjögren's Syndrome: Association of Anti-Ro(SS-A) Antibodies with Vasculitis, Hematologic Abnormalities, and Serologic Hyperreactivity. Ann. Intern. Med. 1983, 98, 155-159. [CrossRef]

20. Cho, C.S.; Park, S.H.; Min, J.K.; Lee, S.H.; Kim, H.Y. Clinical Significances of Antibodies to Ro/SS-A Autoantigens and Its Subtypes in Primary Sjögren's Syndrome. Korean J. Intern. Med. 1997, 12, 176-181. [CrossRef]

21. Ramos-Casals, M.; Anaya, J.-M.; García-Carrasco, M.; Rosas, J.; Bové, A.; Claver, G.; Diaz, L.-A.; Herrero, C.; Font, J. Cutaneous Vasculitis in Primary Sjögren Syndrome: Classification and Clinical Significance of 52 Patients. Medicine 2004, 83, 96-106. [CrossRef]

22. Kontny, E.; Lewandowska-Poluch, A.; Chmielińska, M.; Olesińska, M. Subgroups of Sjögren's Syndrome Patients Categorised by Serological Profiles: Clinical and Immunological Characteristics. Reumatologia 2018, 56, 346-353. [CrossRef]

23. Ramos-Casals, M.; Font, J.; Garcia-Carrasco, M.; Brito, M.-P.; Rosas, J.; Calvo-Alen, J.; Pallares, L.; Cervera, R.; Ingelmo, M. Primary Sjögren Syndrome: Hematologic Patterns of Disease Expression. Medicine 2002, 81, 281-292. [CrossRef] [PubMed]

24. Malladi, A.S.; Sack, K.E.; Shiboski, S.C.; Shiboski, C.H.; Baer, A.N.; Banushree, R.; Dong, Y.; Helin, P.; Kirkham, B.W.; Li, M.; et al. Primary Sjögren's Syndrome as a Systemic Disease: A Study of Participants Enrolled in an International Sjögren's Syndrome Registry. Arthritis Care Res. 2012, 64, 911-918. [CrossRef]

25. Davidson, B.K.; Kelly, C.A.; Griffiths, I.D. Primary Sjögren's Syndrome in the North East of England: A Long-Term Follow-up Study. Rheumatol. Oxf. Engl. 1999, 38, 245-253. [CrossRef] [PubMed]

26. Yachoui, R.; Leon, C.; Sitwala, K.; Kreidy, M. Pulmonary MALT Lymphoma in Patients with Sjögren's Syndrome. Clin. Med. Res. 2017, 15, 6-12. [CrossRef]

27. Manoussakis, M.N.; Kistis, K.G.; Liu, X.; Aidinis, V.; Guialis, A.; Moutsopoulos, H.M. Detection of Anti-Ro(SSA) Antibodies in Autoimmune Diseases: Comparison of Five Methods. Br. J. Rheumatol. 1993, 32, 449-455. [CrossRef]

28. Franceschini, F.; Cavazzana, I. Anti-Ro/SSA and La/SSB Antibodies. Autoimmunity 2005, 38, 55-63. [CrossRef] [PubMed]

29. Egner, W. The Use of Laboratory Tests in the Diagnosis of SLE. J. Clin. Pathol. 2000, 53, 424-432. [CrossRef]

30. Desplat-Jego, S.; Bardin, N.; Larida, B.; Sanmarco, M. Evaluation of the BioPlex 2200 ANA Screen for the Detection of Antinuclear Antibodies and Comparison with Conventional Methods. Ann. N. Y. Acad. Sci. 2007, 1109, 245-255. [CrossRef]

31. Boire, G.; Lopez-Longo, F.J.; Lapointe, S.; Ménard, H.A. Sera from Patients with Autoimmune Disease Recognize Conformational Determinants on the 60-Kd Ro/SS-A Protein. Arthritis Rheum. 1991, 34, 722-730. [CrossRef]

32. Itoh, Y.; Itoh, K.; Frank, M.B.; Reichlin, M. Autoantibodies to the Ro/SSA Autoantigen Are Conformation Dependent. II: Antibodies to the Denatured Form of 52 KD Ro/SSA Are a Cross Reacting Subset of Antibodies to the Native 60 KD Ro/SSA Molecule. Autoimmunity 1992, 14, 89-95. [CrossRef]

33. Itoh, Y.; Reichlin, M. Autoantibodies to the Ro/SSA Antigen Are Conformation Dependent. I: Anti-60 KD Antibodies Are Mainly Directed to the Native Protein; Anti-52 KD Antibodies Are Mainly Directed to the Denatured Protein. Autoimmunity 1992, 14, 57-65. [CrossRef]

34. Charles, P.J.; van Venrooij, W.J.; Maini, R.N. The Consensus Workshops for the Detection of Autoantibodies to Intracellular Antigens in Rheumatic Diseases: 1989-1992. Clin. Exp. Rheumatol. 1992, 10, 507-511. [PubMed]

35. Seror, R.; Ravaud, P.; Bowman, S.J.; Baron, G.; Tzioufas, A.; Theander, E.; Gottenberg, J.-E.; Bootsma, H.; Mariette, X.; Vitali, C.; et al. EULAR Sjogren's Syndrome Disease Activity Index: Development of a Consensus Systemic Disease Activity Index for Primary Sjogren's Syndrome. Ann. Rheum. Dis. 2010, 69, 1103-1109. [CrossRef] [PubMed]

36. Lee, C.-K.; Tsai, C.-P.; Liao, T.-L.; Huang, W.-N.; Chen, Y.-H.; Lin, C.-H.; Chen, Y.-M. Overactive Bladder and Bladder Pain Syndrome/Interstitial Cystitis in Primary Sjögren's Syndrome Patients: A Nationwide Population-Based Study. PLoS ONE 2019, 14, e0225455. [CrossRef] [PubMed]

37. Sène, D.; Cacoub, P.; Authier, F.-J.; Haroche, J.; Créange, A.; Saadoun, D.; Amoura, Z.; Guillausseau, P.-J.; Lefaucheur, J.-P. Sjögren Syndrome-Associated Small Fiber Neuropathy: Characterization From a Prospective Series of 40 Cases. Medicine 2013, 92, e10-e18. [CrossRef] [PubMed]

38. Birnbaum, J.; Lalji, A.; Saed, A.; Baer, A.N. Biopsy-Proven Small-Fiber Neuropathy in Primary Sjögren's Syndrome: Neuropathic Pain Characteristics, Autoantibody Findings, and Histopathologic Features. Arthritis Care Res. 2019, 71, 936-948. [CrossRef] [PubMed]

39. Bernstein, R.M.; Bunn, C.C.; Hughes, G.R. Identification of Antibodies to Acidic Antigens by Counterimmunoelectrophoresis. Ann. Rheum. Dis. 1982, 41, 554-555. [CrossRef]

40. Lee, A.Y.S. A Review of the Role and Clinical Utility of Anti-Ro52/TRIM21 in Systemic Autoimmunity. Rheumatol. Int. 2017, 37, 1323-1333. [CrossRef] 
41. Robbins, A.; Hentzien, M.; Toquet, S.; Didier, K.; Servettaz, A.; Pham, B.-N.; Giusti, D. Diagnostic Utility of Separate Anti-Ro60 and Anti-Ro52/TRIM21 Antibody Detection in Autoimmune Diseases. Front. Immunol. 2019, 10, 444. [CrossRef]

42. Sandhya, P.; Jeyaseelan, L.; Scofield, R.H.; Danda, D. Clinical Characteristics and Outcome of Primary Sjogren's Syndrome: A Large Asian Indian Cohort. Open Rheumatol. J. 2015, 9, 36-45. [CrossRef]

43. Scofield, A.K.; Radfar, L.; Ice, J.; Vista, E.; Anaya, J.-M.; Houston, G.; Lewis, D.; Stone, D.U.; Chodosh, J.; Hefner, K.; et al. Relation of Sensory Peripheral Neuropathy in Sjögren Syndrome to Anti-Ro/SSA. J. Clin. Rheumatol. Pract. Rep. Rheum. Musculoskelet. Dis. 2012, 18, 290-293. [CrossRef] [PubMed]

44. Li, M.; Zhao, Y.; Zheng, W.; Su, J.; Wu, Q.; Jiang, Y.; Xu, D.; Zhang, W.; Zhang, F.; Dong, Y. The diagnostic value of anti-SSA antibody in primary Sjögren's syndrome. Zhonghua Nei Ke Za Zhi 2010, 49, 410-413.

45. Veldhoven, C.H.; Meilof, J.F.; Huisman, J.G.; Smeenk, R.J. The Development of a Quantitative Assay for the Detection of AntiRo/SS-A and Anti-LA/SS-B Autoantibodies Using Purified Recombinant Proteins. J. Immunol. Methods 1992, 151, 177-189. [CrossRef]

46. Orton, S.M.; Peace-Brewer, A.; Schmitz, J.L.; Freeman, K.; Miller, W.C.; Folds, J.D. Practical Evaluation of Methods for Detection and Specificity of Autoantibodies to Extractable Nuclear Antigens. Clin. Diagn. Lab. Immunol. 2004, 11, 297-301. [CrossRef] [PubMed]

47. Tanaka, N.; Muro, Y.; Sugiura, K.; Tomita, Y. Anti-SS-A/Ro Antibody Determination by Indirect Immunofluorescence and Comparison of Different Methods of Anti-Nuclear Antibody Screening: Evaluation of the Utility of HEp-2 Cells Transfected with the $60 \mathrm{KDa}$ SS-A/Ro as a Substrate. Mod. Rheumatol. 2008, 18, 585-592. [CrossRef] [PubMed] 